\title{
Characteristics of a crater glacier at Ushkovsky volcano, Kamchatka, Russia, as revealed by the physical properties of ice cores and borehole thermometry
}

\author{
Takayuki Shiraina, ${ }^{1}$ Yaroslav D. Murav'yev, ${ }^{2}$ Takao Kameda, ${ }^{3}$ Fumihiko Nishio, ${ }^{4}$ Yoko Toyama, ${ }^{4}$ \\ Akiyoshi Takahashi, ${ }^{5}$ Alexander A. Ovsyannikov, ${ }^{2}$ Andrey N. Salamatin, ${ }^{6}$ Kotaro Yamagata ${ }^{7}$ \\ ${ }^{1}$ Institute of Low Temperature Science, Hokkaido University, Sapporo 060-0819, Japan \\ ${ }^{2}$ Institute of Volcanology, Russian Academy of Sciences, Petropavlovsk-Kamchatsky 683006, Russia \\ ${ }^{3}$ Kitami Institute of Technology, Kitami 090-0015, Japan \\ ${ }^{4}$ Center for Environmental Remote Sensing, Chiba University, Chiba 263-8825, Japan \\ ${ }^{5}$ Geo Tecs Co. Ltd, Shirakabe, Nagoya 461-0011, Japan \\ ${ }^{6}$ Department of Applied Mathematics, Kazan State University, Kazan 420008, Russia \\ 7 Joetsu University of Education, Joetsu 943-8512, Japan
}

\begin{abstract}
A glacier at the summit of Ushkovsky volcano, Kamchatka peninsula, Russia, was studied in order to obtain information about the physical characteristics of a glacier that fills a volcanic crater. The glacier has a gentle surface and a concave basal profile with a maximum measured depth of $240 \mathrm{~m}$ at site K2. The annual accumulation rate was $0.54 \mathrm{~m} \mathrm{a}^{-1}$ w.e., and the $10 \mathrm{~m}$ depth temperature was $-15.8^{\circ} \mathrm{C}$. A $211.70 \mathrm{~m}$ long ice core drilled at K2 indicates that (1) the site is categorized as a percolation zone, (2) the stress field in the glacier changes at $180 \mathrm{~m}$ depth from vertical and longitudinal compression with transversal extension, which is divergent flow, to a shear-dominated stress field, and (3) the frequent occurrence of ash layers can be a good tool for dating the ice core. The borehole temperature profiles were considered to be non-stationary, but the linear profile made it possible to estimate the basal temperature and the geothermal heat flux at K2. Assuming constant surface and the basal boundary conditions, we constructed two depth-age relationships at K2. These predicted that the bottom ages of the ice core were about 511 or 603 years.
\end{abstract}

\section{INTRODUCTION}

Ice cores recovered from mid- and low-latitude high mountain glaciers have been used to reconstruct past climate histories on Earth to complement and compare to those obtained from polar regions (e.g. Holdsworth and others, 1989; Wagenbach, 1989; Thompson and others, 1992). Although the ice has a shorter life span, ice cores from these regions are essential to unveil climatic changes occurring in non-polar regions where the time-scale and magnitude of the changes are not necessarily the same as those occurring in polar regions.

There are, however, major disadvantages and limitations to using the high-mountain ice cores from mid- and low latitudes. In addition to the disturbance of the ice-core signals by surface melting (Koerner, 1997), complex flow features in high-mountain glaciers make climatic interpretation of the ice cores difficult. Deposited snow and ice deform rather irregularly because of the complex topographies in mountains (e.g. Lüthi and Funk, 2000). It is thus necessary to understand a glacier's dynamic behavior as well as its mass balance and temperature distribution before analyzing the chemical composition and stable oxygen isotopes of an ice core from the glacier.

To clarify the characteristics of a glacier that fills an active volcanic crater, we investigated the mass balance and subsurface temperature of the glacier at the summit of Ushkovsky, a volcano on the Kamchatka peninsula, Russia. To better understand how the crater glacier deforms in its unique thermophysical environment, we focused on the physical properties of the ice core and the borehole thermometry obtained at the central part of the glacier. We propose two depth-age relationships at the site where the ice cores were drilled. For a future study, we plan to analyze the stable oxygen isotopes and ion chemistry of the ice core. The goal is to reconstruct the past climate over the northern Pacific region; therefore, the major outcome of the present study should provide a physical basis to convert the depth series of the isotopic and chemical signals to the time series of the past climate of this region.

\section{GEOGRAPHICAL AND GLACIOLOGICAL SETTINGS}

\subsection{Ushkovsky volcano}

The summit of Ushkovsky volcano $\left(56^{\circ} 04^{\prime} \mathrm{N}, 160^{\circ} 28^{\prime} \mathrm{E}\right.$; $3903 \mathrm{~m}$ a.s.l.) forms a caldera $4 \mathrm{~km}$ in diameter that is completely covered with a glacier $43 \mathrm{~km}^{2}$ in area. Two craters, Gorshkov and Herz, lie beneath the glacier at the highest part of the volcano (Fig. 1). The volcano is active, but there are no reliable data on its volcanic activity, and only minor fumarolic activity is currently observed (Flerov and Ovsyannikov, 1991). 




Fig. 1. Ushkovsky volcano (3903 m a.s.l.) and the summit craters.

The volcano is still active in the sense that regions on the crater rims are free from ice due to melting of the glacier by intensive geothermal heating. At such locations, subsurface temperatures sometimes reach $70^{\circ} \mathrm{C}$. Intensive melting by geothermal heating is also observed in ice caves that are identified by holes in the glacier surface at Gorshkov crater (Fig. 2). By entering these holes, we found that the ice caves developed along the proximal slope of the crater rim and stretched for several hundred meters in both directions. The ice caves are also traced in the plan view photograph as elongated depressions along the crater rim (Fig. 2).

Murav'yev and Salamatin (1989) estimated the horizontal and vertical velocities of the glacier at the cave as $0.20-0.33$ and $0.33 \mathrm{ma}^{-1}$ ice equivalent, respectively. Murav'yev and Salamatin (1989) and Salamatin and others (2000) concluded that the entire glacier might be melting at its base due to intensive geothermal heating as high as $10 \mathrm{~W} \mathrm{~m}^{-2}$ (Murav'yev and Salamatin, 1989) and $1.0-1.8 \mathrm{~W} \mathrm{~m}^{-2}$ (Salamatin and

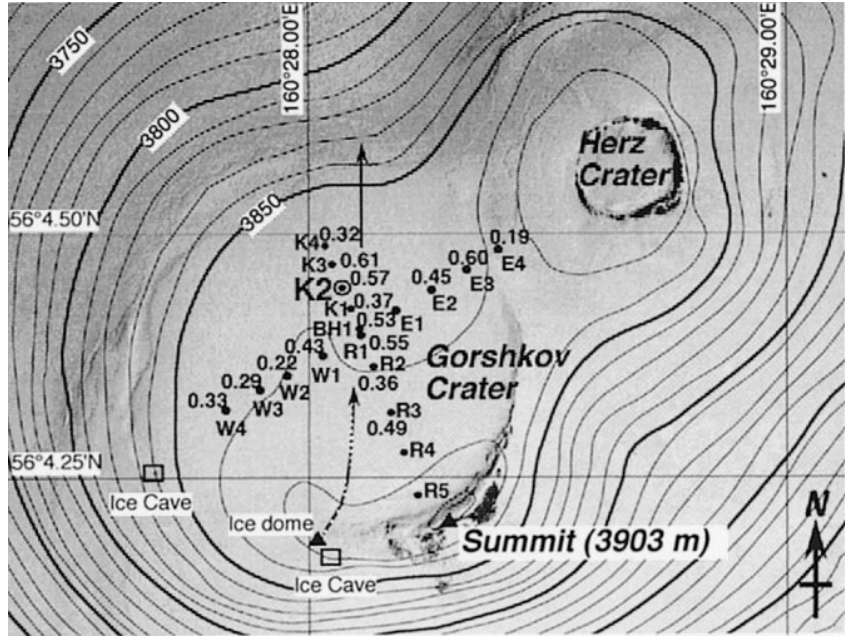

Fig. 2. A plan view of the summit craters, Gorshkov and Herz, and the distribution of annual mass balance $(m)$ for 1997/98. Arrows denote a principal flow direction indicated by the surface gradient. Subsurface caves starting from an ice cave at the southwest rim are clearly indicated by depressions along the west to northwestern rim of the Gorshkov crater.

others, 2000). Introduction of such high geothermal heat fluxes resulted in estimation of younger ages of the glacier bottom in their mathematical depth-age calculations ( 650 years; Salamatin and others, 2000).

\subsection{Geometry of the glacier filling the Gorshkov crater}

Surface and bed topographies of the glacier filling the Gorshkov crater were determined by a topographic survey

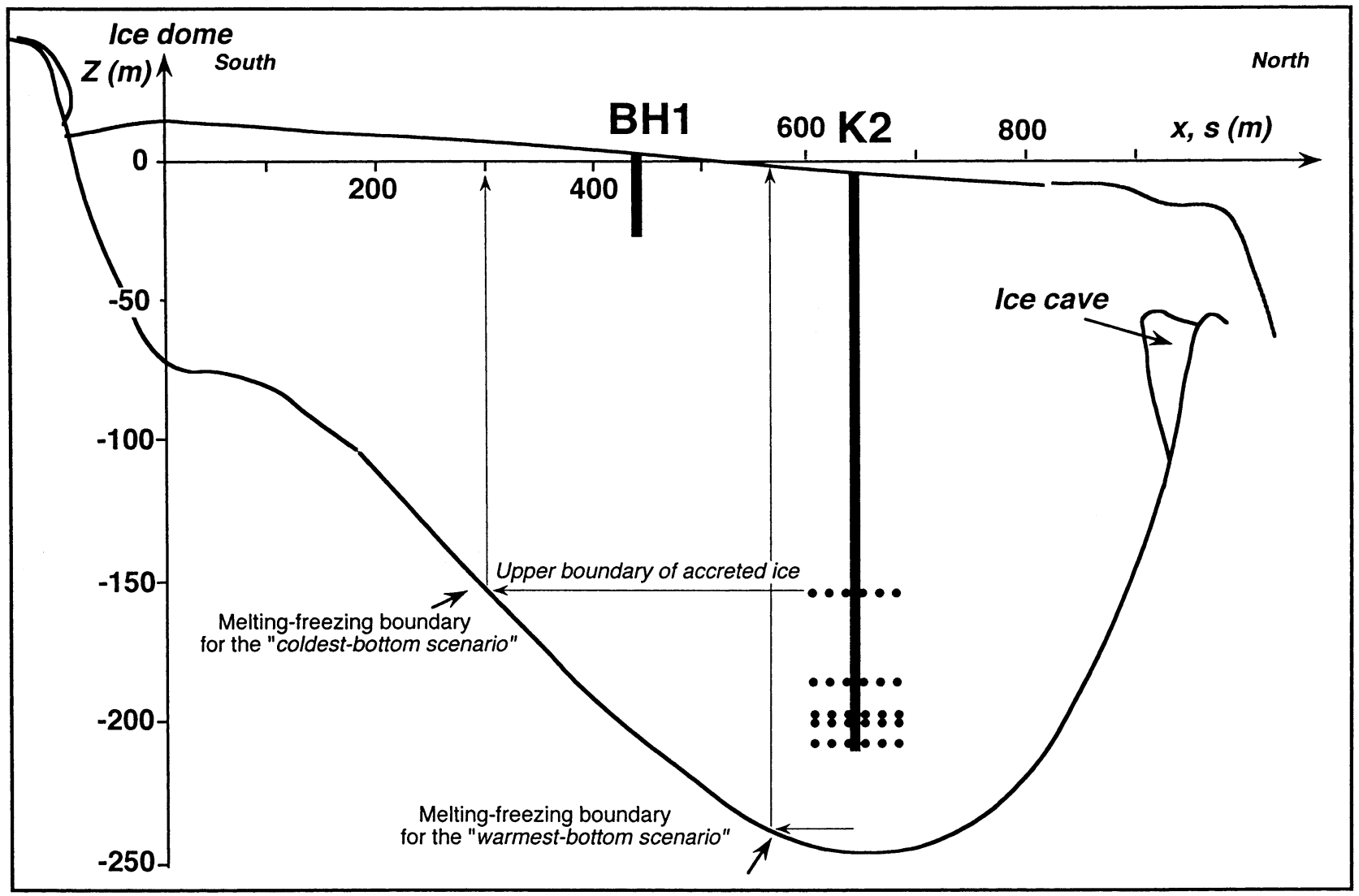

Fig. 3. Cross-section of the glacier filling Gorshkov crater. Marginal subsurface caves are depicted schematically. A series of dotted layers crossing the ice core at $K 2$ are the basal accreted ice layers that appeared below $154 \mathrm{~m}$. Two solid columns indicate the boreholes drilled in 1996 ( BH1) and 1998 ( K2). 
conducted in 1997 with a hand-held global positioning system, a theodolite and an impulse radio-echo sounding system (Matsuoka and others, 1997, 1999; Shiraiwa and others, 1999a). A total of 18 points denoted by solid dots in Figure 2 were fixed with triangulation to determine a principal flow direction of the glacier according to its surface topography.

The diameter of the submerged crater is approximately $800 \mathrm{~m}$ and the rim is exposed only at the southeastern edge to form the highest summit of Ushkovsky volcano (3903 m). The surface inclination of the glacier downward to the north was measured as $2^{\circ}$ along the survey line R $5-\mathrm{K} 4$. We did not find any appreciable inclination along the survey transect from W4-E4. The principal flowline, therefore, is from an ice dome at the southern edge of the crater along a direction somewhat east of K4 as shown by an arrow in Figure 2.

Figure 3 shows a cross-section along the survey transect R5-K4 of the glacier that fills the Gorshkov crater. This crater is a slightly north-shifted concave bowl with a maximum measured ice thickness of $240 \mathrm{~m}$ at K2. It can also be seen from this cross-section, in conjunction with the plan view (Fig. 2), that the ice flows beyond the crater rim into the caldera at the northern end of the crater. This spillover implies that the glacier is not confined to the crater.

\subsection{Mass balance}

To measure the mass balance at the surface, a series of snow stakes were installed at the glacier on 2 August 1996. Such mass-balance measurements were repeated during 10-18 June 1997 and also on 19 June 1998. The water-equivalent balances (in meters) at each point are shown in Figure 2 for the period 18 June 1997 to 19 June 1998.

In the balance year 1996/97, the mass balances were measured at three points: $0.38 \mathrm{~m}$ at $\mathrm{BH} 1,0.38 \mathrm{~m}$ at $\mathrm{E} 4$ and $0.54 \mathrm{~m}$ at W4. During 1997/98, mass balances were obtained at 15 points. The values range from $0.19 \mathrm{~m}$ at $\mathrm{E} 4$ to $0.61 \mathrm{~m}$ at $\mathrm{K} 3$, with an average value of $0.42 \pm 0.14 \mathrm{~m}$. The mass balance tends to be higher in the central part of the glacier and lower in the western part. The lowest value recorded at $\mathrm{E} 4$ is due to its location, which is a wind-blown saddle. Although we have no information about the winter mass balance for this glacier, it is probable that wind scouring occurs near the western part of the crater. Redistribution of the snow in the central part of the crater is likely to be small because clear seasonal variations in oxygen and hydrogen isotopes were found in the ice cores.

The mass balance recorded in the balance year 1997/98 at $\mathrm{K} 2$, the drilling site, was $0.57 \mathrm{~m} \mathrm{a}^{-1}$ w.e. This is comparable with the average accumulation rate of $0.57 \mathrm{~m} \mathrm{a}^{-1}$ w.e. that was reconstructed for the last 27 years from a shallow ice core recovered in 1996 at BH1 (Shiraiwa and others, 1997).

\subsection{Surface snow temperatures}

Snow temperatures were continuously measured at $\mathrm{BH}$ for 1 year using a $27 \mathrm{~m}$ borehole drilled in August 1996. Platinum resistance thermometers with an accuracy of $\pm 0.1^{\circ} \mathrm{C}$ were installed at depths of 1, 2, 4, 5, 8, 10 and $27 \mathrm{~m}$ on 2 August 1996 for automatic measurements every 3 hours. They were collected a year later when the snow surface had increased by $0.79 \mathrm{~m}$ in height from that on 2 August 1996. Because the measurements were done without any maintenance, no correction was made for the depths of sensors according to the changing level of the surface.

Figure 4 shows monthly and annual mean temperature



Fig. 4. Monthly and annual average snow-temperature profiles measured at BH1 (Gorshkov crater) from August 1996 to fuly 1997.

profiles at BH1 during 1996/97. Shallow parts of the profiles fluctuated with the seasonal cycles, but there were no indications of persistent melting temperatures at the surface. The annual average temperature at $1 \mathrm{~m}$ depth $(1.79 \mathrm{~m}$ depth at the end of the observation period) was $-16.6^{\circ} \mathrm{C}$. The amplitude of the fluctuations decreases with depth. At $10 \mathrm{~m}$ depth, the average temperature was $-15.8^{\circ} \mathrm{C}$ and the average amplitude was $1.3^{\circ} \mathrm{C}$. The seasonal fluctuation becomes 0 at $27 \mathrm{~m}$ depth, where the snow temperature was constant at $-14.6^{\circ} \mathrm{C}$ throughout the year. In later discussions, the annual average temperature profile given in Figure 4 is called profile BHl (1996/97) average.

\section{IGE-GORE DRILLING AND ANALYTICAL METHODS}

Following the preliminary shallow ice coring done in 1996 and 1997 (Shiraiwa and others, 1997, 1999a), a full-depth ice coring was attempted at site K2 from 20 to 30 June 1998 (Shiraiwa and others, 1999b). We used an electromechanical drill (Takahashi, 1996) to recover an ice core 0.8-1.0 m long and $94 \mathrm{~mm}$ in diameter in each drilling run. After a total drilling time of 103 hours, the drilling was stopped at $211.70 \mathrm{~m}$ depth, approximately $28 \mathrm{~m}$ above the bedrock. The many ash layers in the core made the drilling difficult because they wore the cutters very quickly.

The ice cores recovered were immediately subjected to stratigraphic observations and bulk density measurements. We made macroscopic in situ stratigraphic observations with the aid of a fluorescent light to check several structural properties: the bubble concentration, the alternation of bubbly and less bubbly layers, the occurrence of ash layers and the inclin- 
ation of layered structures. These layers include ash layers and relatively clear layers of ice. The results were sketched on a chart paper with the same scale as that of the ice cores.

All of the ice cores were then transported at a sufficiently low temperature to a cold laboratory $\left(-20^{\circ} \mathrm{C}\right)$ of the Institute of Low Temperature Science, Hokkaido University. At this laboratory, ice samples were cut approximately every $20 \mathrm{~m}$ to make thin sections for measurements of crystal-orientation fabrics. Following the method described in Langway (1958) and Kamb (1962), the ice-fabric measurements were made using vertical thin sections sampled from layers that displayed rich and uniform bubble concentration. This was to avoid a possible influence of melting on grain growth. Approximately 200 crystals were measured per sample if that number was available; these data were then plotted on the lower hemisphere of a Schmidt equal-area net by rotating the readings in the horizontal plane.

In the field, the temperature of the wall of the borehole was measured immediately after the drilling operation using a device developed by Kameda and others (1993). This device consists of a cylindrical weight with three pantographs that touch the borehole wall. A compact thermistor sensor was attached at one of the pantographs and measured the temperature of the wall with an accuracy of $\pm 0.06^{\circ} \mathrm{C}$. Because the digital multimeter had a measurement error of $\pm 0.04^{\circ} \mathrm{C}$, the final absolute accuracy of the measurement is $\pm 0.1^{\circ} \mathrm{C}$. Wall temperatures were measured at depths of 2.50, 5.00, 10.00, 15.00, 20.00, 40.00, 60.0080 .00 , 99.60, 119.20, 140.20, 158.10, 178.10, 188.10, 198.10, 203.10, 208.10 and $211.70 \mathrm{~m}$. At each depth, the temperature was measured for 2 hours at certain time intervals, and the final reading was used for the temperature at the depth. The temperature profile obtained at this time is called profile K2 (1998).

The borehole was maintained after the measurements so that the temperature profile could be measured 1 year later on 6-7 August 1999. These measurements of the air in the borehole were made using four platinum resistance thermometers with an accuracy of $\pm 0.1^{\circ} \mathrm{C}$. The temperatures were measured at each depth for 1 hour with four sensors. During this time, the temperatures were measured every $2 \mathrm{~min}$ at every $10 \mathrm{~m}$ depth level. The measurements were made only above $140 \mathrm{~m}$ because of unexpected sticking of the sensors at this depth. The data recorded in each sensor were cross-checked to exclude operational and systematic errors. The four data series were then stacked into one profile to make an interannual comparison possible. This temperature profile is called profile K2 (1999).

\section{PHYSICAL PROPERTIES OF THE ICE CORE}

\subsection{Stratigraphic features}

Two distinct types of layering were observed in the firn and ice cores: firn layers that have not been affected by melting, and ice layers formed by melting and subsequent refreezing in the surface snow. The melt type was easily identified, with the aid of transmitted light, as clear layers devoid of bubble inclusions, even below the pore close-off depth. The nonmelting type was identified as layers including variable numbers of uniformly distributed bubbles (Fig. 5). The two types of layering are interbedded and of varying thickness.

The stratigraphic features indicate that surface melting occurs at this glacier despite its cold environment. The drilling site is thus considered to be located at the percolation

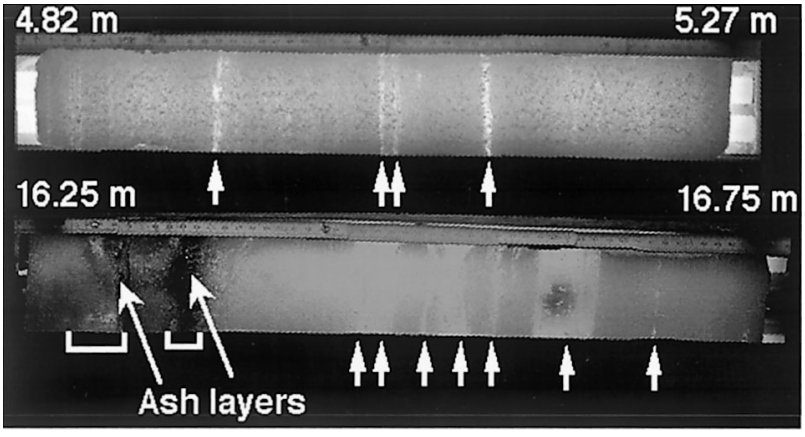

Fig. 5. Ice-core sections showing two representative layers: firn layers that have not been affected by melting (whitish parts) and melt features formed by melting and subsequent freezing (clear parts indicated by arrows). Two layers of melt features associated with ash layers are found at the top of the lower core section.

zone of Benson (1962). We call the refrozen melt layers melt features because they sometimes appear as vertical ice glands. There are only two possible causes for melting in this glacier: (1) the air temperature occasionally exceeds $0^{\circ} \mathrm{C}$ in summer, and (2) volcanic ash covers the snow surface and induces melting by reducing the albedo of the snow surface. Support for the warm-temperature cause is the correlation between the summer atmospheric $(700 \mathrm{hPa})$ temperatures over the Kamchatka peninsula and melt-feature percentages in the $27 \mathrm{~m}$ ice core recovered at $\mathrm{BH}$ (Shiraiwa and others, 1997). The volcanic-ash cause occurs unpredictably and induces melting even at temperatures as low as $-10^{\circ} \mathrm{C}$. This implies that the occurrence of a melt feature does not necessarily indicate that a warmer summer occurred.

We have constructed two series that show how melt features vary with depth in the ice core. The melt-feature percentage (MFP) was calculated according to the following relation (Koerner, 1977; Kameda and others, 1995):

$$
\mathrm{MFP}=\frac{0.9 S_{\mathrm{i}}}{0.9 S_{\mathrm{i}}+\rho_{\mathrm{f}} S_{\mathrm{f}}} \times 100
$$

where $S_{\mathrm{i}}$ refers to areas with melt features, $S_{\mathrm{f}}$ refers to areas with firn and bubbly layers after the pore close-off depth, 0.9 $\left(\mathrm{Mg} \mathrm{m}^{-3}\right)$ is the density of the melt features, and $\rho_{\mathrm{f}}$ is the density of firn and bubbly ice $\left(\mathrm{Mg} \mathrm{m}^{-3}\right)$. These areas were identified on a flat surface cut along the ice and firn cores. The unit length for the measurement of MFP was $1 \mathrm{~m}$ throughout the ice core.

The original MFP profile in Figure 6 was made without paying attention to ash layers. All the less bubbly layers were counted as melt features. The climatic MFP in Figure 6 excluded possible influences of volcanic eruptions on the formation of melt features by subtracting the ice layers associated with ash layers. This is because we considered the less bubbly layers associated with ashes not to be of climatic origin, but instead due to the volcanic eruptions. The location of ash layers in the melt features is variable: some ash layers appear in the lowest part of the melt features (Fig. 5), and others are located in either the upper or the middle parts. For all varieties, we simply subtracted the ice layers including ash layers in the calculation of climatic MFP. Therefore, this is a first approximation to the past summer temperatures, and it must be checked in the future by comparing with a stable oxygen isotopic profile.

In the original MFP profile, several peaks of high MFP appear throughout the entire depth. Prominent peaks were found at depths of 160, 105, 85, 70 and $60 \mathrm{~m}$, where the MFPs 




Climatic MFP (\%) Number of ash layers Inclination of ash layers

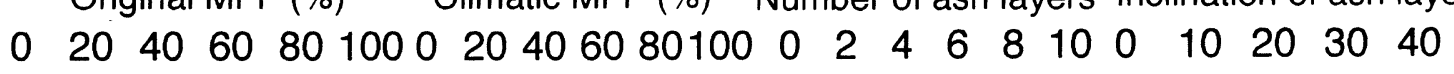
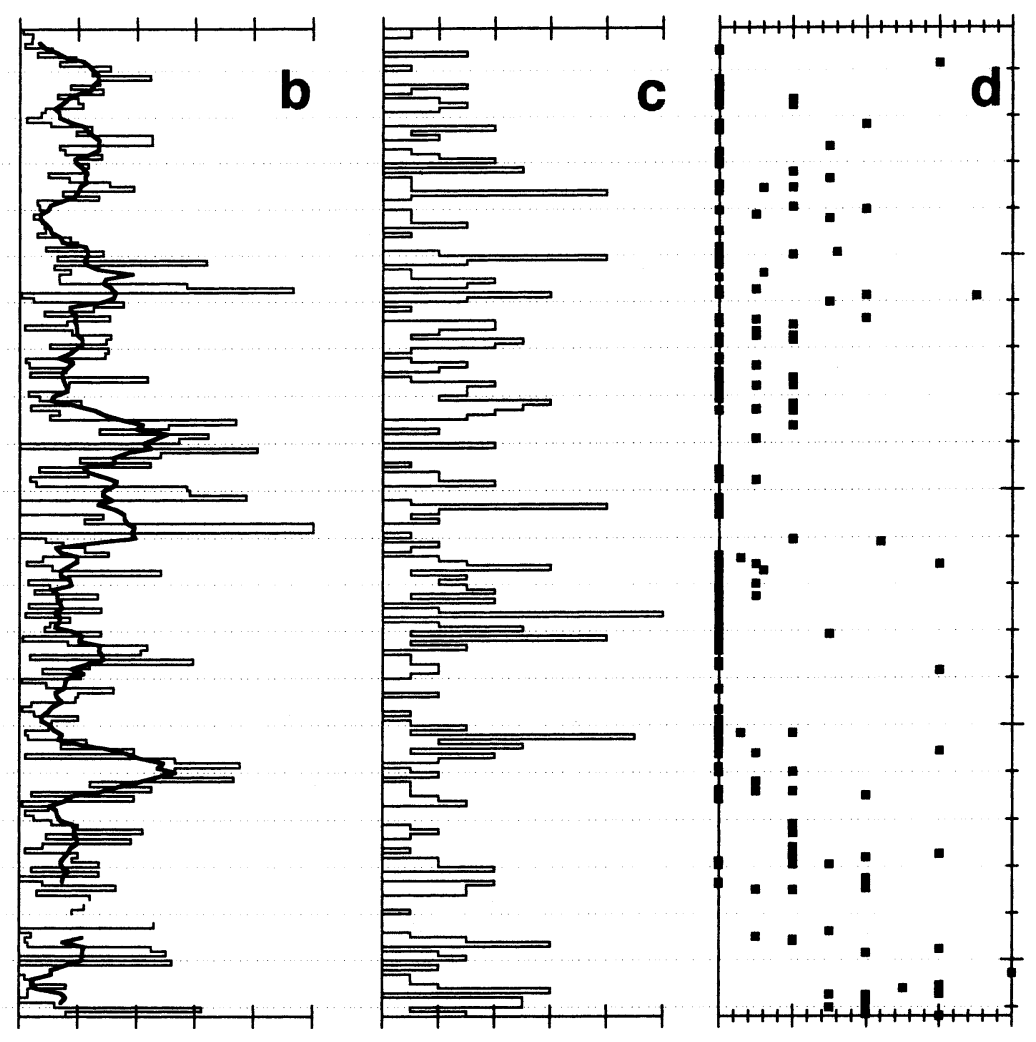

Fig. 6. Distributions of ( a) original MFP, (b) MFPexcluding ash layers, (c) number of ash layers within an ice-core length of $1 \mathrm{~m}$, and $(d)$ inclination angle $\left({ }^{\circ}\right)$ of the ash layers from the horizontal plane. For the MFP, running average curves of $7 m$ are also shown.

exceeded $50 \%$. In these peaks, a possible reason for the high MFP was a volcanic eruption since many of the peaks disappeared after subtracting the melt features associated with ash (cf. the climatic MFP in Fig. 6). This means that the activity of nearby volcanoes significantly affected the physical properties of the ice core in the crater glacier.

\subsection{Tephrochronology}

Macroscopic observations (Fig. 6) indicated a total of 328 ash layers in the $211.70 \mathrm{~m}$ ice core. They are distributed throughout the depth of the ice core. The appearances of the ash layers are variable, from a densely compacted thick one to a sparsely scattered aggregate of ashes. The thickest ash layers were those observed at 35.49, 86.44, 102.82 and $138.45 \mathrm{~m}$, and each was at least $1.0 \mathrm{~cm}$ thick.

The mineral composition of the ashes enabled us to determine the sources of the ash layers at depths of 12.04, 35.49 and $102.82 \mathrm{~m}$. The whitish, pumice-like fine ashes at 12.04 and $35.49 \mathrm{~m}$ depth contained plagioclase, pyroxene and hornblende. These are typical components of ashes erupted from Bezymianny volcano, which is approximately $14 \mathrm{~km}$ southeast of the glacier. The last catastrophic eruption occurred in March 1956 (Flerov and Ovsyannikov, 1991), and is identified as a sequence of ash layers spanning the ice-core section between 35.49 and $35.30 \mathrm{~m}$. The ice cores in this section show clear ice with very few bubbles, indicating that rapid melting occurred near the ash deposition. The average accumulation rate from 1956 to 1998 is thus estimated as $0.54 \mathrm{~m} \mathrm{a}^{-1}$ w.e. by using the depth-density information provided below.

The ash at $12.04 \mathrm{~m}$ depth was also identified as Bezymianny ash since one of the authors (Y.M.) made a continuous pit observation at this glacier during 1985/86 and found this layer near the surface at that time (Murav'yev and Salamatin, 1989). Ash layers at depths of 1.43 and $0.81 \mathrm{~m}$ were identified through our continuous pit observations as Bezymianny ashes erupted on 9 May and 5 December 1997.

The mineral composition of ashes at $102.82 \mathrm{~m}$ contained plagioclase, olivine and pyroxene, which identify them as ash from Klyuchevskoi volcano located just beside Ushkovsky volcano. This is one of the most active volcanoes in Kamchatka, with eruptions almost every year. Among these eruptions, that in 1829 was extremely hazardous. In the ice core, we found many ash layers that probably originated in Klyuchevskoi volcano. The ash at $102.82 \mathrm{~m}$ depth was the thickest and most concentrated, so we attribute it to the 1829 eruption.

Besides the ash layers, we observed clear-ice layers containing no bubbles but scattered and rounded rock fragments in the lower part of the ice core. These are schematically shown as dots in Figure 3. They started to appear at $154 \mathrm{~m}$ depth and then appeared at 179, 195, 198, 200 and $208 \mathrm{~m}$. The thickness of each horizontal layer varied from 10 to $100 \mathrm{~cm}$, and the layers are clearly distinguished from the neighboring layers. We believe that the layers were most probably accreted at an ice-bedrock interface where bottom melting occurs sporadically along the glacier bottom. The refrozen water at the bottom might have been accreted into the glacier after entraining rock fragments from the bottom.

We measured the inclination angle of each ash layer from the horizontal plane normal to the core axis. It was impossible to determine the azimuth of the core, so we measured the maximum polar angle for each ash layer (Fig. 6). Horizontal ash layers were found from the surface to $180 \mathrm{~m}$ depth, whereas ash layers were always inclined, some as much as $30^{\circ}$ from the horizontal plane, at deeper 




Fig. 7. Depth-density relationship for the ice-core data obtained at K2. The solid line is the mean-square approximation.

levels. Although inclined layers were found at shallower depths, such layers are not necessarily caused by glacial flow; some of the ash layers must have been deposited at an angle to the surface. Because no horizontal layers are detected below $180 \mathrm{~m}$, we conclude that only depths below $180 \mathrm{~m}$ indicate noticeable influence of rotational movement of the glacier that suggests shear strain.

\subsection{Bulk density}

Figure 7 shows the bulk density distribution with depth. There is considerable scatter in the profile above the pore close-off depth at around $55 \mathrm{~m}$ because the bulk measurements were made for each core segment without distinguishing firn from ice. The close-off depth at $55 \mathrm{~m}$ was almost the same as the $58 \mathrm{~m}$ predicted by Shiraiwa and others (1997) using Herron and Langway's (1980) densification model. The latter estimate used the depth-density data for the upper $27 \mathrm{~m}$ obtained at $\mathrm{BH} 1$ on the same glacier.

The entire part of the profile of the present bulk density $\rho$ can be fitted, by mean-square approximation, as

$$
\rho=\rho_{\mathrm{i}}\left(1-c_{\mathrm{s}} \mathrm{e}^{-\gamma h}\right),
$$

where $\rho_{\mathrm{i}}$ is the density of pure ice $\left(918 \mathrm{~kg} \mathrm{~m}^{-3}\right), c_{\mathrm{S}}$ is the ice porosity at the surface $(0.55), h$ is the depth from the glacier surface in meters, and $\gamma$ is a coefficient $\left(0.038 \mathrm{~m}^{-1}\right)$. The values of the parameters are slightly different from those obtained by Salamatin and others (2000) (Table 1). The difference is ascribed to the difference of the location where the
Table 1. Comparison of physical properties and parameters between sites BH1 and $K 2$

\begin{tabular}{lccc}
\hline & BH1 & K2 (predicted) & K2 (measured) \\
\hline$h_{\max }(\mathrm{m})$ & 185 & 240 & 240 \\
$\Delta_{*}(\mathrm{~m})$ & 168 & 223 & 226 \\
$C_{\mathrm{s}}$ & 0.5 & Assumed & 0.55 \\
$\gamma\left(\mathrm{m}^{-1}\right)$ & 0.03 & to be same & 0.038 \\
$b_{\text {ice }}\left(\mathrm{m} \mathrm{a}^{-1}\right)$ & 0.6 & as BH 1 & 0.59 \\
$q_{0}\left(\mathrm{~W} \mathrm{~m}^{-2}\right)$ & 0.25 or 1.4 & Assumed as 1.4 & $0.12 \pm 0.01$ \\
$w_{0}\left(\mathrm{~m} \mathrm{a}^{-1}\right)$ & 0 or 0.11 & Assumed as 0.15 & 0 \\
$\theta\left(b / w_{0}\right)$ & - & 0.25 & $0.07 / 0.25$ \\
Bottom age (years $)$ & - & 610 & $829 / 639$ \\
& & & \\
\hline
\end{tabular}

Notes: Values for $\mathrm{BH} 1$ and $\mathrm{K} 2$ (predicted) are from Salamatin and others (2000). $h_{\max }$, real ice thickness $(\mathrm{m}) ; \Delta_{*}$, ice-equivalent ice thickness $(\mathrm{m})$; $C_{\mathrm{s}}$, ice porosity at the surface; $\gamma$, coefficient in the density-depth profile approximation; $b$, annual accumulation rate in ice $\left(\mathrm{m} \mathrm{a}^{-1}\right) ; q_{0}$, geothermal heat flux $\left(\mathrm{W} \mathrm{m}^{-2}\right) ; w_{0}$, basal melting rate $\left(\mathrm{m} \mathrm{a}^{-1}\right) ; \theta$, relative melt rate.

ice cores were obtained and, more directly, to a more detailed density analysis of the ice core in this study than in the previous one.

The total thickness of the glacier at K2 was calculated as $207 \mathrm{~m}$ w.e. and $226 \mathrm{~m}$ ice equivalent from the density data in Table 1. These values will be used to construct the depth-age relationship at $\mathrm{K} 2$ in the final part of this paper.

\subsection{Crystal-size and -orientation fabrics}

Figure 8 shows photographs of the vertical thin sections in cross-polarized light and the Schmidt equal-area net plots of the crystal $c$-axis orientations projected on the horizontal planes. The center of the circle represents the vertical direction in the Schmidt equal-area net.

We did not observe any systematic change in the size of crystals with depth, as is the case in most cold glaciers and ice sheets. The temperature of the glacier is highly variable, from $-15.8^{\circ} \mathrm{C}$ at $10.00 \mathrm{~m}$ to $-4.2^{\circ} \mathrm{C}$ at $211.70 \mathrm{~m}$, as discussed in the next section. This temperature range favors polygonization and recrystallization as mechanisms that inhibit crystal growth, although we observed neither strain shadows nor sutured grain boundaries above sample No. 460 (202.03$202.11 \mathrm{~m}$ ). These features suggest polygonization and dynamic recrystallization, respectively. The crystals in sample No. 483 $(211.42-211.50 \mathrm{~m})$ are slightly elongated in the direction of about $45^{\circ}$ from the core axis, which suggests shear stress at this depth. This is why the influence of deformation on grain-size might explain the lack of appreciable grain growth with depth. Also, a relatively high concentration of chloride and sulfate ions in the ice might have influenced the crystal growth by impeding grain-boundary migration (Alley and others, 1986); this is because the average concentrations of 553 and $3468 \mu \mathrm{g} \mathrm{L}^{-1}$ of each ion in the core from 0 to $110 \mathrm{~m}$ depths (Shiraiwa and others, unpublished information) are high enough to support this effect.

In contrast, the $c$-axis orientations seem to change with depth. In the upper $160 \mathrm{~m}$ of the core, the $c$ axes appear to be quasi-uniformly distributed (Nos. 137, 188 and 376) and, in some cases, show a weak girdle-type cluster around a vertical plane (Nos. 220 and 322). The $c$ axes start to have a preferred orientation below $180 \mathrm{~m}$. At first, they tend to concentrate in a single maximum at depths from 182 to $202 \mathrm{~m}$ (Nos. 413 and 460), and then they have a single maxi- 




63.05-63.13 m

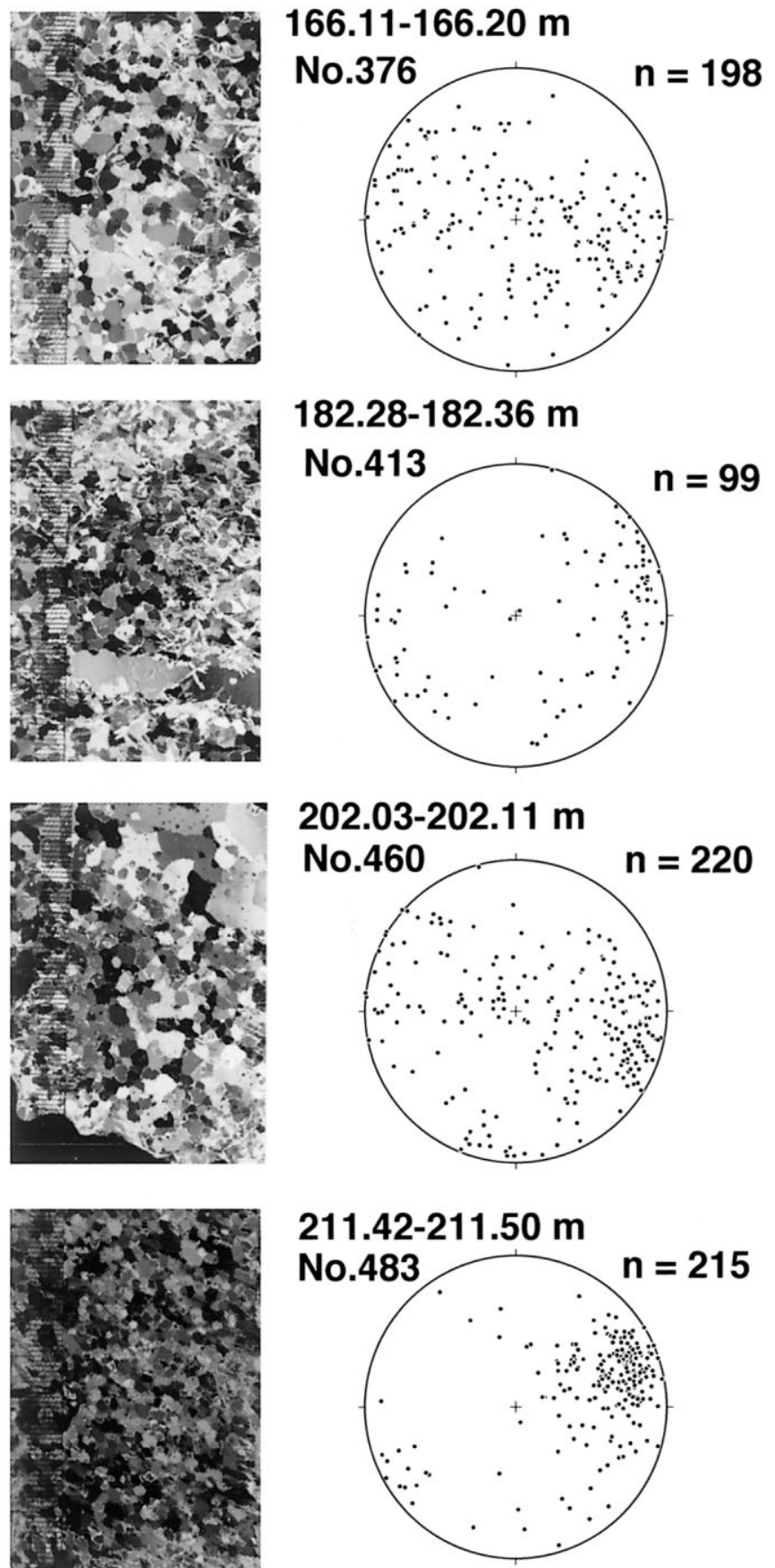

Fig. 8. Cross-polarized photographs of vertically cut samples and c-axes orientation fabrics projected for the lower hemisphere of Schmidt equal-area nets approximately every $20 \mathrm{~m}$ along the ice core. The number of samples for the c-axes orientation measurement are in the right upper corner of each diagram.

mum at $211 \mathrm{~m}$ (No. 483) where the preferred orientation is inclined approximately $22^{\circ}$ from the horizontal plane.

A great girdle-type fabric often appears in a convergent flow field of vertical compression with longitudinal extension such that the direction of the circle--girdle axis is perpendicular to the flow direction. This occurs in ice cores at Vostok and Mizuho in Antarctica (Fujita and others, 1987; Lipenkov and others, 1989), but here we cannot determine the flow direction from elongation of the crystals and information on the natural geomagnetization. The $\mathrm{K} 2$ site is slightly downstream from the center of the crater, and the ice thickness increases considerably along the flowline from the dome to the K2 site (Fig. 3). Therefore, it is most likely that the girdle pattern was formed by a flow field of compression in both the flow $(x)$ and vertical $(z)$ directions, with extension to the transverse $(y)$ directions to the flow; that is, divergent flow.
It is unusual to see a fabric starting to develop already in the uppermost $100 \mathrm{~m}$. The fabric strength seems to be mainly determined by the total vertical strain, and because the vertical strain rate is comparatively high at this location $\left(0.54 \mathrm{~m} \mathrm{a}^{-1} / 207 \mathrm{~m}=2.6 \times 10^{-3} \mathrm{a}^{-1}\right)$, fabrics should evolve much more rapidly with depth and time than in ice cores from the large polar ice sheets.

The single maximum that appeared in the deepest part of the cores can be produced by simple shear, which is the most probable flow field near the bottom $(88 \%$ depth below the surface). However, the compression axis may not be vertical but inclined to approximately $22^{\circ}$ from the horizontal plane. This might indicate a complex flow field near the bottom of the glacier due to the concave profile of the crater glacier. The layers of ash that are inclined as much as $30^{\circ}$ below $180 \mathrm{~m}$ (Fig. 6) are concomitant with the fabric patterns, suggesting a rotating flow with the simple shear at this depth. 


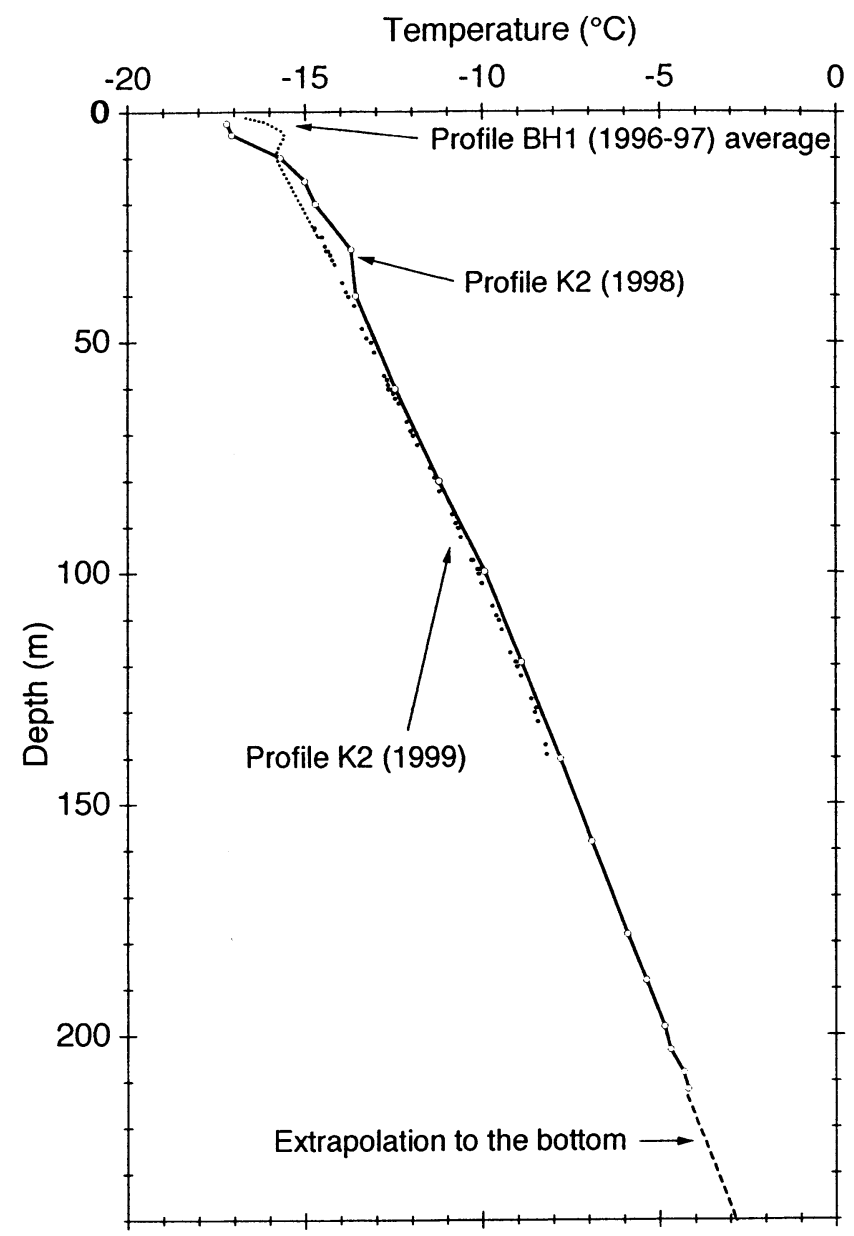

Fig. 9. Temperature profiles measured for BH1 and $\mathrm{K} 2$. The circles, large (dark) and small dots are the average profiles for K2 (1998), K2 (1999) and BH1 (1996/97), respectively. The dashed line is the extrapolation to the bottom of the glacier according to the measured gradient for the profile K2 (1998).

\section{BOREHOLE TEMPERATURES}

Figure 9 shows three series of vertical profiles of the temperature measured along the borehole. In spite of differences in time and location, the profiles are quite similar, except for the upper $15 \mathrm{~m}$ where a seasonal fluctuation exists (Fig. 4). At $\mathrm{K} 2$, the depths from 25 to $40 \mathrm{~m}$ have temperatures that differ between 1998 and 1999 by about $0.5^{\circ} \mathrm{C}$. Because the profile of the BHl (1996/97) average connects smoothly to K2 (1999), the difference of $0.5^{\circ} \mathrm{C}$ between $\mathrm{K} 2$ (1998) and K2 (1999) must have occurred due to non-climatic change between 1998 and 1999. One possibility could be the influence of the drilling on the 1998 temperature profile. The mechanical drill frequently passed by the upper part of the borehole during the drilling operation, which may have increased the original temperatures at the upper depths.

To the accuracy of the measurements $\left( \pm 0.1^{\circ} \mathrm{C}\right)$, there is no significant difference in the temperatures: the temperature profiles nearly coincide between 40 and $140 \mathrm{~m}$. Therefore, the profiles between 40 and $140 \mathrm{~m}$ are probably not influenced by our drilling, and so can be used for the analysis of the thermophysics of the glacier.

The temperature increases nearly linearly with depth, from $-14.7^{\circ} \mathrm{C}$ at $20.00 \mathrm{~m}$ to $-4.2^{\circ} \mathrm{C}$ at $211.70 \mathrm{~m}$. The profile is almost completely linear from $99.60 \mathrm{~m}\left(-9.9^{\circ} \mathrm{C}\right)$ to the bottom of the borehole $\left(-4.2^{\circ} \mathrm{C}\right)$. In the accumulation area of a glacier, the steady-state temperature has a concave profile because of vertical advection of cold firn into the glacier (Paterson, 1994). The linearity of the profile suggests that the temperature profile of this glacier is not stationary. This is likely due to the different rate of production of melt features with depth, as shown in section 4.1 (Fig. 6), because the variable production rates should have released different amounts of latent heat that must have significantly influenced the temperature profile. It is also possible (see below) that variable geothermal heat fluxes along the flowline are the reason the temperature is non-stationary. In either case, we conclude that the highly variable thermal state of the glacier is one of the characteristics of glaciers that fill active volcanic craters.

\section{INTERPRETATION}

\subsection{Basal condition of the crater glacier}

In previous theoretical thermodynamic analysis (Salamatin and others, 2000), we estimated the bottom melting rate at $\mathrm{BH} 1$ as $0.11 \pm 0.004 \mathrm{~m} \mathrm{a}^{-1}$. After drilling the ice core at $\mathrm{K} 2$, we obtained more complete data concerning the local physical properties of the glacier, as described in sections 4 and 5 . We now examine the basal condition using the newly obtained dataset listed in Table 1 , and propose a more detailed and precise estimate of the geothermal heat flux for the $\mathrm{K} 2$ site and thereby the depth-age relationship at K2.

Owing to the linearity of the temperature profile at K2, we extrapolate the profile to the deepest part. The temperature gradient of $0.051^{\circ} \mathrm{C} \mathrm{m}^{-1}$ used for the extrapolation to the glacier bottom was obtained from the lower $112 \mathrm{~m}$ of the profile between 99.60 and $211.70 \mathrm{~m}$, where the profile was straight. The bottom temperature at $240 \mathrm{~m}$ is thus calculated as $-2.8 \pm 0.1{ }^{\circ} \mathrm{C}$. This value is colder than the melting temperature, even if we take into account that the melting point is depressed due to pressure by $0.15-0.20^{\circ} \mathrm{C}$. Therefore, the bottom of the glacier at $\mathrm{K} 2$ is probably frozen to the bed.

The volcanic heat flux can also be estimated. The volcanic heat flux $q_{0}$ is given by the conventional heat-conduction equation $q_{0}=\lambda_{\mathrm{i}}(\partial T / \partial z)_{\text {bottom }}$, where the thermal conductivity $\lambda_{\mathrm{i}}$ is $2.3 \mathrm{~W} \mathrm{~m}^{-1} \mathrm{~K}^{-1}$ for basal temperatures in the lower $100 \mathrm{~m}$ of the glacier. As a result, we obtained a volcanic heat flux $q_{0}$ of $0.12 \pm 0.01 \mathrm{~W} \mathrm{~m}^{-2}$. This is approximately $1.5-2.6$ times larger than the average heat flux on the continents (0.046- $0.077 \mathrm{~W} \mathrm{~m}^{-2}$; Paterson, 1994), and one to two orders of magnitude lower than predicted for this glacier by theoretical considerations (Murav'yev and Salamatin, 1989; Salamatin and others, 2000).

\subsection{Depth-age relationships}

Earlier we derived a simplified analytical solution for the depth-age relationship at the glacier in the Gorshkov crater using the melting condition at the bottom (Salamatin and others, 2000). In this solution, the age $t$ of the ice for an iceequivalent thickness $\Delta$ of the glacier is

$$
\begin{aligned}
t= & \frac{2 s \Delta_{*}(\nu+1)}{b s_{*}(1-\theta)}\left\{1-[\theta+(1-\theta) \zeta]^{\frac{1}{\nu+1}}\right\} \\
& \cdot\left(1-\frac{s}{4 s_{*}}\left\{1+[\theta+(1-\theta) \zeta]^{\frac{1}{\nu+1}}\right\}\right),
\end{aligned}
$$

where $s$ is the distance from the ice dome, $s_{*}$ is the distance from the ice dome to the deepest point $\mathrm{K} 2(650 \mathrm{~m}), \Delta_{*}$ is the ice-equivalent thickness at the deepest point $\mathrm{K} 2(223 \mathrm{~m}), \nu$ is 
the exponent in the approximation for the ice-flow-tube width (here taken as $\nu=1$ for divergent radial flow), $\zeta$ is the normalized vertical coordinate as expressed by distance from the glacier bottom measured in terms of equivalent thickness of pure ice, $b$ is the annual accumulation rate of ice $\left(0.60 \mathrm{~m} \mathrm{a}^{-1}\right)$, and $\theta$ is the relative melt rate.

In this solution, we used a relative melt rate $\theta$ of 0.25 . This is the ratio between the bottom melt rate and the surface accumulation rate expressed as an area mean over the glacier. In this case, the maximum age of the bottom ice at K2 was calculated to be about 610 years (AD 1388) (Salamatin and others, 2000).

We now know that the geothermal heat flux is not uniform along the flowline. Thus, we should revise $\theta$ so as to fit these new data. To estimate the mean melt-rate ratio $\theta$, we might assume that along the first half of the flowline the local melt rate varies from 1 to 0 and then remains 0 until K2. These assumptions are based on the three considerations mentioned in the previous sections: (1) the basal melt rate $\sim 0.33 \mathrm{~m} \mathrm{a}^{-1}$ (Murav'yev and Salamatin, 1989) is nearly equivalent to the accumulation rate near the rim where the ice cave exists, (2) the basal melt rate is most probably zero at K2, and (3) the uppermost accreted ice layers, described in section 4.2, might have originated in the region where the melted bottom changed to a frozen bottom at $s=300 \mathrm{~m}$ in Figure 3. This is the "coldest-bottom scenario". Because the melting-freezing boundary cannot be decided precisely with the available dataset, we also show the "warmest-bottom scenario". This case assumes that only the deepest part of the glacier is frozen to the bed, and the melting-freezing boundary was located at $s=560 \mathrm{~m}$.

The mean melt rate $\theta$ for the two limiting cases is calculated from

$$
\langle\theta\rangle=(\nu+1) \int_{0}^{S_{\mathrm{m}}} S^{\nu}\left(1-\frac{S}{S_{\mathrm{m}}}\right) \mathrm{d} S=\frac{S_{\mathrm{m}}^{\nu+1}}{\nu+2},
$$

where $S_{\mathrm{m}}$ is the ratio between the distance to the meltingfreezing boundary and the distance to the site of consideration. In this case, we assume the local melt rate varies from 1 at the crater rim (ice dome) to 0 at a distance of $300 \mathrm{~m}$ (the coldest) or $560 \mathrm{~m}$ (the warmest). The former case locates the melting-freezing boundary at the same level at which the accreted ice layers start to appear in the ice core at K2 (Fig. 3 ). In our case $\nu \approx 1$ (divergent flow); therefore, $S_{\mathrm{m}}$ equals 0.462 for the coldest-bottom scenario and equals 0.862 for the warmest-bottom scenario. As a result, the estimate of $\theta$ becomes 0.07 for the coldest and 0.25 for the warmest-bottom scenario.

We constructed two versions of the depth-age relationships at K2 with the newly obtained boundary conditions (see Table 1; Fig. 10). The depth-age relationship obtained by $\theta=0.07$ predicts significantly different ages in the lower parts in comparison with those predicted using $\theta=0.25$. The ages of the bottom of the glacier at $\mathrm{K} 2$ and the deepest point of the borehole were 829 (AD 1169) and 603 (AD 1395) years for the coldest-bottom scenario, and 639 (AD 1359) and 511 (AD 1487) years for the warmest-bottom scenario, respectively. The older ages in our coldest-bottom scenario are mainly the result of bottom compression due to a more extensive frozen bottom.

The two possible depth-age relationships can be evaluated against the dated ash layers found at depths of $12.04 \mathrm{~m}$ (AD 1985), $35.49 \mathrm{~m}$ (AD 1956) and $103.0 \mathrm{~m}$ (AD 1829) m. In the

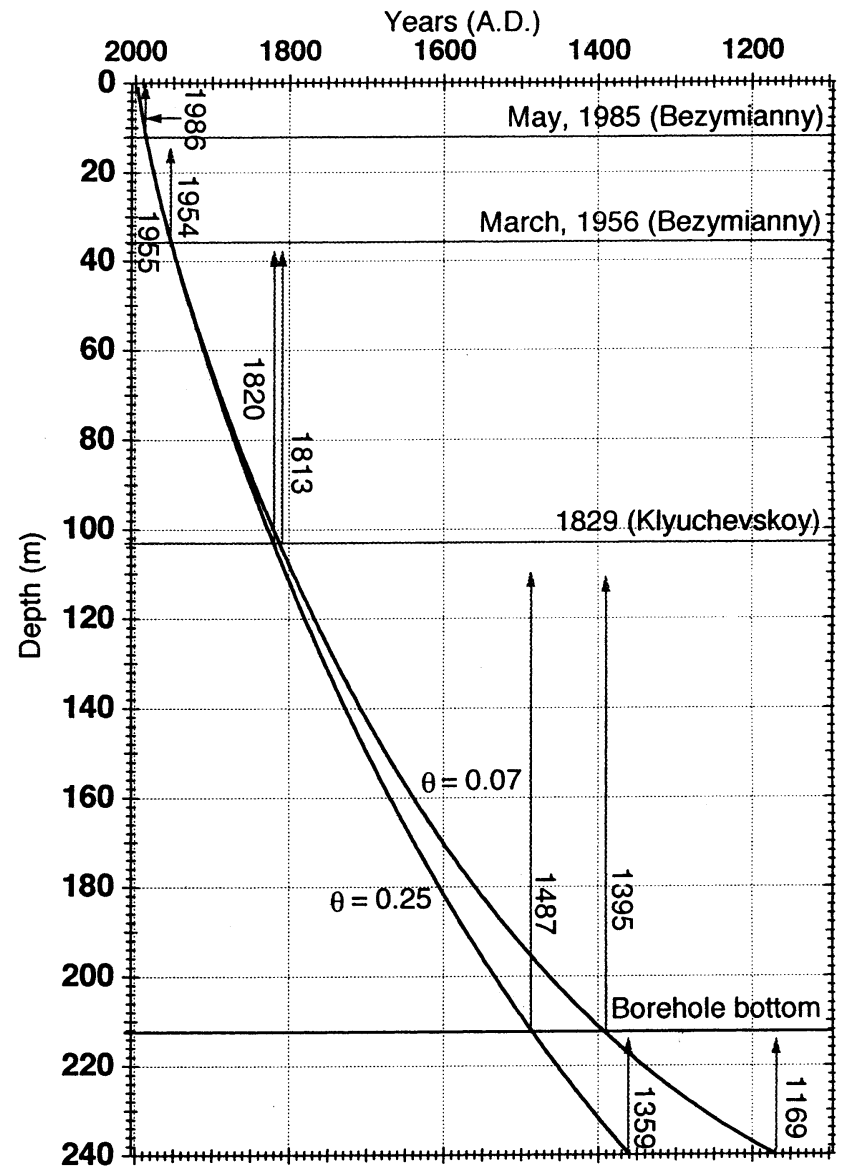

Fig. 10. Two tentative depth-age relationships constructed with newly obtained bottom boundary conditions $(\theta=0.07$ and 0.25) according to the model by Salamatin and others (2000). The positions of three dated ash layers are also shown.

coldest-bottom scenario, each depth of the dated layers gives AD 1986, AD 1954 and AD 1813, and the differences between the real dates and the predictions increased from 1 year at $12.04 \mathrm{~m}$ to 16 years at $103.0 \mathrm{~m}$, whereas in the warmest-bottom scenario each depth of the ash layers is dated as AD 1986, AD 1955 and AD 1820, respectively.

The results show that the warmest-bottom scenario gives the better estimates. The depth-age relationship given by the warmest-bottom scenario can thus provide a first basis in considering the age, and therefore the thinning history, of the ice core. Equation (3) assumes steady-state conditions with a constant accumulation rate and constant basal boundary condition. The input of newer data, such as accumulation-rate history, should reduce the small discrepancy that remains.

\section{CONCLUSIONS}

The glacier filling Gorshkov crater on Ushkovsky volcano has a diameter of $800 \mathrm{~m}$, a gently inclined $\left(2^{\circ}\right)$ surface, a concave basal profile and a maximum depth of $240 \mathrm{~m}$. The average accumulation rate at the central part of the glacier (K2) was $0.54 \mathrm{ma}^{-1}$ w.e. with moderate spatial variability $\left( \pm 0.14 \mathrm{~m} \mathrm{a}^{-1}\right.$ w.e. $)$ over the glacier. Year-round measurements of the temperature near the surface show that the surface and $10 \mathrm{~m}$ depth temperatures were $-16.6^{\circ}$ and $-15.8^{\circ} \mathrm{C}$, respectively.

A $211.70 \mathrm{~m}$ long ice core drilled at $\mathrm{K} 2$ contained firnderived ice and melt features that most probably were pro- 
duced by both high summer temperatures and radiationinduced melting related to volcanic-ash cover. Crystalorientation fabrics were random to slightly girdled above $180 \mathrm{~m}$ depth. Below this depth, the fabric tended to concentrate in a single maximum peak inclined about $22^{\circ}$ from the horizontal plane. This implies a change in the flow field at $180 \mathrm{~m}$ depth, from mostly vertical and longitudinal compression with transversal extension (divergent flow) to a simple shear-dominated rotating flow. This interpretation was supported by the pattern of inclination of ash layers in the ice cores.

The borehole temperature profiles were linear, and the bottom temperature at $\mathrm{K} 2$ was estimated at $-2.8 \pm 0.1^{\circ} \mathrm{C}$, which predicts a geothermal heat flux of $0.12 \pm 0.01 \mathrm{~W} \mathrm{~m}^{-2}$.

Using the accumulation rate of $0.59 \mathrm{~m} \mathrm{a}^{-1}$ of ice and the relative melt rates $\theta=0.07$ and 0.25 at the bottom, we constructed two depth-age relationships according to the theory of Salamatin and others (2000). These relationships allow the age of the ice core to be estimated.

The glacier in the volcanic crater is found to be non-stationary in its thermodynamics; hence, the age of the glacier ice is probably very sensitive to the surface and the basal conditions. In the case of the Gorshkov ice cap, the maximum age at the bottom at $\mathrm{K} 2$ (240 m deep) is calculated to be $830-640$ years. Because the age of ice cores in volcanic craters is relatively easily determined using dated ash layers, ice-core signals such as stable oxygen isotopes and ion chemistry will be invaluable for a high-resolution reconstruction of past climate history provided that the unique influence of the glacier dynamics is properly considered.

\section{ACKNOWLEDGEMENTS}

The authors would like to express their gratitude to D. Kobayashi, T. Hondoh, R. Naruse and staff of the workshop, all of whom are from the Institute of Low Temperature Science, Hokkaido University, for their continuous support for this project. A. Miyamoto of the Kitami Institute of Technology supported the first author in conducting the fabric analyses of the ice core. S. Takahashi of the Kitami Institute of Technology kindly permitted us to use his institute's mechanical drill. L. A. Mysak of McGill University kindly edited the English of the first draft. Comments from T. Jóhannesson of the Icelandic Meteorological Office and two anonymous reviewers were helpful in revising the manuscript in the final stage. Discussions with A. Ohmura and H. Blatter of Eidgenössische Technische Hochschule (ETH), Zürich, during the first author's stay at ETH were also invaluable. We would like to thank them for their support and hospitality. The Schmidt-net plot was facilitated by the software "STEREONET ver. 4.9 " by R.W. Allmendinger. This study was supported by Grants-in-Aid for International Scientific Research (No. 08041090: principal investigator D. Kobayashi) and Grants-in-Aid for Scientific Research on Priority Areas (B) (2) (No. 10204201: principal investigator T. Hondoh), both from the Ministry of Education, Science, Sports and Culture of Japan.

\section{REFERENGES}

Alley, R. B., J. H. Perepezko and C. R. Bentley. 1986. Grain growth in polar ice: II. Application. f. Glaciol., 32(112), 425-433.

Benson, C. S. 1962. Stratigraphic studies in the snow and firn of the Greenland ice sheet. SIPRE Res. Rep. 70.

Flerov, G. B. and A. A. Ovsyannikov. 1991. Vulkan Ushkovski [Ushkovsky volcano]. In Fedotov, S. A. and Yu. P. Masurenkov, eds. Deistruyushie Vulkaniy Kamchatki [Volcanoes of Kamchatka]. Vol.1. Moscow, Nauka, 156-165.

Fujita, S., M. Nakawo and S. Mae. 1987. Orientation of the $700 \mathrm{~m}$ Mizuho core and its strain history. Proc. NIPR Symp. Polar Meteorol. Glaciol. 1, 122-131.

Herron, M. M. and G. C. Langway, Jr. 1980. Firn densification: an empirical model. f. Glaciol., 25(93), 373-385.

Holdsworth, G., H. R. Krouse, M. Nosal, M. J. Spencer and P. A. Mayewski. 1989. Analysis of a 290-year net accumulation time series from Mt. Logan, Yukon. International Association of Hydrological Sciences Publication 183 (Symposium at Baltimore 1989-Snow Cover and Glacier Variations), 71-79.

Kamb, W. B. 1962. Refraction corrections for universal stage measurements. I. Uniaxial crystals. Am. Mineral., 47(3), 227-245.

Kameda, T., S. Takahashi, K. Goto-Azuma, S. Kohshima, O. Watanabe and J. O. Hagen. 1993. First report of ice core analyses and borehole temperatures on the highest icefield on western Spitsbergen in 1992. Bull. Glacier Res. 11, 51-61.

Kameda, T., H. Narita, H. Shoji, F. Nishio, Y. Fujii and O. Watanabe. 1995. Melt features in ice cores from Site J, southern Greenland: some implications for summer climate since AD 1550. Ann. Glaciol., 21, 51-58.

Koerner, R. M. 1977. Devon Island ice cap: core stratigraphy and paleoclimate. Science, 196(4285), 15-18.

Koerner, R. M. 1997. Some comments on climatic reconstructions from ice cores drilled in areas of high melt. F. Glaciol., 43(143), 90-97. (Erratum: 43(144), p. 375-376.).

Langway, C. C., Jr. 1958. Ice fabrics and the universal stage. SIPRE Tech. Rep. 62.

Lipenkov, V.Ya., N. I. Barkov, P. Duval and P. Pimienta. 1989. Crystalline texture of the $2083 \mathrm{~m}$ ice core at Vostok Station, Antarctica. F. Glaciol., 35(121), 392-398.

Lüthi, M. and M. Funk. 2000. Dating of ice cores from a high Alpine glacier with a flow model for cold firn. Ann. Glaciol., 31, 69-79.

Matsuoka, K. and 8 others. 1997. [Radio-echo sounding of the Ushkovsky ice cap, Kamchatka, Russia.] Seppyo, 59(4), 257-262. [InJapanese with English summary.]

Matsuoka, K. and 7 others. 1999. Radio echo sounding at the summit ice cap of Ushkovsky volcano, Kamchatka. In Naruse, R., ed. Cryospheric studies in Kamchatka II. Sapporo, Hokkaido University. Institute of Low Temperature Science, 20-24.

Murav'yev, Ya. D. and A. N. Salamatin. 1989. Balans massy i termodinamicheskii regim lednika v kratere Ushkovskogo vulkana [Mass balance and thermal regime of a crater glacier at Ushkovskii volcano]. Vulkanologiya i Seysmologiya, 11 (3), 85-92. (Transl. in Volc. Seis., 11(3), 1990, 411-423.)

Paterson, W. S. B. 1994. The physics of glaciers. Third edition. Oxford, etc., Elsevier.

Salamatin, A. N., Y. D. Murav'yev, T. Shiraiwa and K. Matsuoka. 2000. Modelling dynamics of glaciers in volcanic craters. f. Glaciol., 46(153), 177-187.

Shiraiwa, T., Ya. D. Murav'yev and S. Yamaguchi. 1997. Stratigraphic features of firn as proxy climate signals at the summit ice cap of Ushkovsky volcano, Kamchatka, Russia. Arct. Alp. Res., 29(4), 414-421.

Shiraiwa, T. and 7 others. 1999a. Geophysical and paleoclimatic implications of the Ushkovsky ice cap in Kamchatka. In Naruse, R., ed. Cryospheric studies in Kamchatka II. Sapporo, Hokkaido University. Institute of Low Temperature Science, 8-19.

Shiraiwa, T. and 6 others. 1999b. [Ice core drilling at Ushkovsky ice cap, Kamchatka, Russia.] Seppyo, 61(1), 25-40. [In Japanese with English summary.]

Takahashi, A. 1996. [Development of a new shallow ice core drill.] Seppyo, 58(1), 29-37. [In Japanese.]

Thompson, L. G., E. Mosley-Thompson and P. A. Thompson. 1992. Reconstructing interannual climate variability from tropical and subtropical ice-core records. In Diaz, H. F. and V. Markgraf, eds. El Niño. Historical and paleoclimatic aspects of the Southern Oscillation. Cambridge, Cambridge University Press, 295-322.

Wagenbach, D. 1989. Environmental records in alpine glaciers. In Oeschger, H. and C. C. Langway, Jr, eds. The environmental record in glaciers and ice sheets. Chichester, etc., John Wiley and Sons, 69-83. 